\title{
Supporting Public Access to Research Results
}

\section{P. Scott Lapinski, David Osterbur, Joshua Parker, and Alexa T. McCray}

\begin{abstract}
We posed the question of what services an academic library can best provide to support the NIH Public Access Policy. We approached the answer to this question through education, collaboration, and tool-building. As a result, over the last four years we have engaged over 1,500 participants in discussions of public access to research results, forged alliances with dozens of partners, and built online tools to ease the process of complying with the NIH policy. We conclude that librarians working in collaboration with other key constituencies can have a positive impact on improving access to the results of scientific research.
\end{abstract}

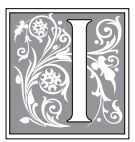

n April 2008, the National Institutes of Health (NIH) policy on enhancing public access to publications resulting from NIH-funded research went into effect. This policy, known as the NIH Public Access Policy, implements a section of Public Law 110-161 and states: The Director of the National Institutes of Health shall require that all investigators funded by the NIH submit or have submitted for them to the National Library of Medicine's PubMed Central an electronic version of their final, peer-reviewed manuscripts upon acceptance for publication, to be made publicly available no later than 12 months after the official date of publication: Provided, That the NIH shall implement the public access policy in a manner consistent with copyright law. ${ }^{1}$

The rationale for this law is two-fold: 1) since NIH supported research is ulti- mately funded by the public, the public has the right to have access to the results of that research, and 2) since the NIH has an obligation to monitor and promote the research that it funds, with the primary goal of advancing science and improving human health, it needs to collect and archive the publications that result from that research.

Prior to congressional enactment of the NIH policy, we at the Countway Library of Medicine at Harvard Medical School were already working to raise awareness and promote participation in PubMed Central. In early 2006, we began an instructional program to help researchers better understand author copyright transfer agreements, the advantages of using a Creative Commons addendum, ${ }^{2}$ and the benefits of submitting manuscripts into PubMed Central (at that time still a voluntary process $\left.{ }^{3}\right)$.

P. Scott Lapinski is Digital Resources Librarian, David Osterbur is Director of Public and Access Services, Joshua Parker is Access Services Librarian, and Alexa T. McCray is Associate Director in Francis A. Countway Library of Medicine at Harvard Medical School; e-mail: p_lapinski@hms.harvard.edu,david_osterbur@hms. harvard.edu, joshua_parker@hms.harvard.edu, alexa_mccray@hms.harvard.edu. (c) 2014 P. Scott Lapinski, David Osterbur, Joshua Parker, and Alexa T. McCray, Attribution-NonCommercial (http://creativecommons. org/licenses/by-nc/3.0/) CC BY-NC 
As part of this effort, we conducted several seminars to discuss these topics in the context of improving access to biomedical scholarship. Attendance at these initial seminars was low, and interest among authors was limited. We also developed an open DSpace repository called HMScholar and populated it with a collection of open access articles published by Harvard biomedical and health science researchers. Using both PubMed Central and HMScholar to demonstrate the ease of use, improved discovery, and access to biomedical literature was relatively easy. It quickly became apparent, however, that stimulating interest among faculty in contributing manuscripts to the repository would be more challenging.

When the NIH mandatory policy was signed into law in 2007, we, like several other medical school libraries, ${ }^{4}$ sought to expand our outreach efforts to NIHfunded principal investigators to let them know of their responsibility to make the results of their research publicly available. We worked together with the Harvard University Office for Sponsored Programs in establishing guidelines for compliance with the policy. In doing so, we relied heavily on Michael Carroll's early white paper $^{5}$ on the challenges that the $\mathrm{NIH}$ policy would entail for institutions and their prinicipal investigators. These early meetings positioned Countway to host a website containing information about the NIH policy for all of Harvard, including background information on the policy, author addenda, and letters to help support authors in retaining the necessary rights to their work while complying with the NIH policy. ${ }^{6}$

\section{Literature Review}

\section{Scholarly Communication in the Digital Age}

The NIH Public Access Policy can be understood in the context of significant changes in the scholarly communication landscape in the past two decades. The rise of the public Internet, with its browsable web interface, made access to digital materials simple and immediate; at the same time, journal prices were escalating at an unacceptable rate. This led to an increasing interest on the part of librarians and others to seek alternative models of scholarly communication. ${ }^{7}$ The Association of Research Libraries took an early position on these issues with the establishment of an Office of Scholarly Communication in 1990, followed in 1998 by the creation of the highly effective Scholarly Publishing and Academic Resources Coalition (SPARC), which since that time has served as a comprehensive resource and advocate for broader access to the scientific literature. ${ }^{8}$ SPARC was an early and strong supporter of the NIH Public Access Policy, and it has worked for the passage of the Federal Research Public Access Act that would require that all U.S. government agencies with annual grant portfolios of over $\$ 100$ million mandate that manuscripts of peer-reviewed journal articles that arose from their funding be made available in a publicly accessible database. ${ }^{9}$

Librarians, other information professionals, and, in some cases, researchers themselves, have questioned the high and continuously rising prices of scientific journals, particularly at a time when it would appear that at least some of the major costs of publishing, namely the printing and distribution costs, have dropped sharply (see, for example, the discussion in Moghaddam ${ }^{10}$ ). This has led to a number of studies that analyze the business models of journal publishers (see especially King ${ }^{11}$ ), and other studies that propose new revenue models. ${ }^{12}$ Some publishers have weighed in on these issues, arguing that publishers add value and that alternative models, such as open access, may put the entire scientific publishing enterprise at risk. ${ }^{13}$ Efforts such as the Public Library of Science (PLoS) arose out of dissatisfaction with the current publishing model and resulted in multiple high-quality open access PLoS journals in the life sciences. ${ }^{14}$ 


\section{Open Access Movement}

The last ten years have seen a growing open access movement that has involved a proliferation of open access journals, with the Directory of Open Access Journals currently listing thousands of journals published in more than 118 countries, ${ }^{15}$ as well as the establishment of disciplinespecific repositories and institution-based repositories, with many of the latter being initiated by academic librarians. ${ }^{16}$ The literature on open access makes a distinction between two complementary strategies, referred to as 1) "gold" access, which is generally represented by journals that make their contents openly available on the date of publication, and 2) "green" access, which refers to manuscripts that are openly available predominantly through self-archiving, in some cases after an embargo period. ${ }^{17}$ One of the first formal statements about open access was made at a meeting in Budapest, Hungary, in 2002, which argued for the "world-wide electronic distribution of the peer-reviewed journal literature and completely free and unrestricted access to it by all scientists, scholars, teachers, students, and other curious minds." ${ }^{\prime 18}$ The Budapest statement notes that scientific knowledge is a public good and therefore needs to be available to all, whether this is for educational purposes, including general scientific literacy, or whether it is, for example, available to patients as they search for information on prevention or treatment of serious conditions and diseases. ${ }^{19}$

In spite of the obvious benefits of open access to researchers, namely that their own work is available to a much broader audience and that they have greater access to the work of others, many researchers do not see publishing in an open access journal or even self-archiving their work as a high priority. ${ }^{20}$ Their concern is rather with publishing in a high-impact journal and the positive effect that this has on promotion and tenure, and most appear to be satisfied with the access to the scientific literature that they have in their university settings. ${ }^{21}$

\section{Role of the Librarian in Scholarly Communication}

In an effort to educate researchers about the benefits of making their research more openly available, and, in response to the growing open access movement, many academic libraries have begun formal programs in scholarly communication. Libraries have established either official Scholarly Communication Offices or have hired individuals whose primary job it is to conduct outreach on scholarly communication issues. ${ }^{22}$ Librarians have the opportunity to exercise their existing competencies in outreach, education, and data management, while at the same time taking on new roles and developing new competencies to meet the challenges involved in promoting open access at their universities and among their faculty. ${ }^{23}$

While most librarians have positive attitudes toward open access policies and the broader open access movement, they sometimes find it challenging to engage in open access activities in their local settings. ${ }^{24}$ In response, library associations as well as individual libraries have begun offering training programs in a variety of areas related to scholarly communication, including the critical aspect of authors retaining their rights when faced with signing publisher copyright transfer agreements. ${ }^{25}$

Recently, Carpenter et al. undertook a study involving twenty ARL library directors, with the goal of envisioning the library's role in scholarly communication in the year 2025. ${ }^{26}$ They identified three "possible futures" for librarians: 1) the status quo, 2) increased support/leadership, and 3) more of a central player. These possible futures eventually resulted in six different scenarios that were presented to the library directors in the form of a survey. While some of the directors felt that all of the scenarios represented different aspects of what libraries are already doing today, all agreed that the rapidly changing landscape of scholarly communication demanded that libraries define their role in this landscape and 
that collaboration with a broad range of constituencies would be the key to their success.

\section{Methods}

The Francis A. Countway Library of Medicine is located on the Longwood medical campus of Harvard University and serves as the primary research library for Harvard Medical School (HMS), Harvard School of Public Health, and the Harvard School of Dental Medicine. Since HMS alone has more than 11,000 faculty members working on thousands of NIH grants across the campus and at affiliated hospitals, and because these grants are generally administered locally, one of the most immediate challenges was to identify effective ways for us to connect with faculty at multiple locations. A given principal investigator (PI) will often have appointments at one or more affiliated institutions while also being a faculty member at HMS. Similarly, postdoctoral researchers often work at labs and clinics throughout the system. Our goal has been to support Harvard-affiliated researchers regardless of where they are located or where their grants are administered. This has involved working with some 17 separate organizations, often with a variety of personnel at each institution, including institutional leaders, faculty, librarians, and administrators.

Our initial focus was on providing Harvard researchers with multiple services to support the requirements of the NIH policy. A variety of workflows already existed throughout Harvard and its affiliated hospitals for the management of faculty bibliographies, submitting grants to the NIH, and acquiring PubMed Central ID (PMCID) numbers. Our best opportunities for reaching out to authors were to insert our services within these workflows and to partner with groups on campus and at the NIH. In March 2008, we introduced several online services and an ambitious round of informational seminars on campus and at affiliated hospitals. The sessions focused on providing researchers with direct support in navigating the requirements of the NIH policy. We provided examples of when to use an author copyright addendum if presented with a contract from a publisher that did not provide a clause for manuscript submission to PubMed Central (PMC). We discussed repository submissions to PMC and offered handson tutorials for using the NIH Manuscript Submission System (NIHMS). As NIH services were expanded over the next two years, we integrated instruction for using the MyNCBI Bibliography and eRA Commons to manage compliance activity for a PI's published output.

We knew from earlier in-house data analyses that HMS faculty publish more than 300 articles per week. Working on the basis of a conservative estimate that 20 percent of these articles have NIH grant support, we anticipated a surge of Harvard authors needing support in complying with the mandate. Although this estimate was roughly accurate, the authors and PIs requesting support did not materialize overnight. In fact, most of those seeking assistance with the new $\mathrm{NIH}$ mandate were not the authors or PIs at all, but rather their administrative assistants.

If authors and PIs chose to delegate the PMC deposit responsibilities to an assistant, it would have been necessary for each assistant to set up an individual NIHMS account. Recognizing the inefficiencies in this approach, we contacted the PubMed Central administrators at $\mathrm{NIH}$ to discuss streamlining the process. As a result, Countway Library was provided with 1) a "Publishers" account in the NIHMS system, which allowed library staff to deposit manuscripts on behalf of anyone (author, PI, or an assistant), and 2) access to an FTP drop box where Countway staff could batch-submit multiple manuscripts using a predefined Document Type Definition, a process similar to that used by publishers depositing batches directly into PMC. 
For the end user at Harvard, we constructed an HMScholar submission form that provides us with all the information we need to relay the submission to the PubMed Central NIHMS system. (See figure 1.)

The HMScholar deposit mechanism can be used by anyone at Harvard. Upon submission, an e-mail is sent to both the Digital Resources Librarian and the Countway reference department's "Ask-A-Librarian" e-mail tracking sys- tem. Once a submission is made in the local system and e-mail notification has been received by the HMScholar team, Countway staff log into the NIHMS system through our account, transfer the metadata, and upload the manuscript via the NIHMS utility. From this single login, staff can also check the status of past submissions. When we discover items in need of attention, we contact the original submitter to help resolve any outstanding issues.

\begin{tabular}{|l|l|}
\hline & FIGURE 1 \\
\hline
\end{tabular}


Perhaps more important than the question of who would deposit the manuscripts in PubMed Central was the question of how we might inform Harvard researchers of our HMScholar services. Promoting library seminars on the Longwood campus followed the same methods we use to advertise any other library instructional session. For us to reach the majority of HMS faculty, however, we needed to better understand the environment at each of the affiliated hospitals. For this segment of our user community, we were able to build on our relationships with hospital librarians at each location. With their assistance, we identified contacts within local grants offices and developed outreach opportunities unique to each location. These included the use of digital displays at hospitals, newsletters, and e-mail announcements of upcoming events at each location. Using the local communications tools helped us effectively broadcast our announcements about the NIH policy compliance seminars. More importantly, these avenues prompted researchers to inquire about the NIH policy even if they could not attend a seminar. In all cases, it allowed us to promote Countway as a support center for questions or problems regarding the NIH policy.

As more departments across the Harvard system experienced the complexities and subtleties of the NIH policy, the questions that we received helped us better shape our instructional seminars and develop new online tools to assist faculty members and their research teams. It quickly became apparent that the greatest number of questions would surface shortly before an NIH grant application or progress report deadline. As faculty and administrators began to organize their bibliographies to demonstrate to the NIH how they had used federal funds awarded to them by a previous grant, many found that they were now required to provide PMCID numbers for all of the papers related to that grant. Other questions quickly followed, including:
- I see the citation in PubMed, so why doesn't it have a PMCID number?

- Why can't I just download the publisher's PDF and put it into PubMed Central?

- Why didn't the publisher give me a PMCID number; aren't they required to by law?

And sometimes even:

- What is the NIH Public Access Policy?

When patrons approach library staff with such general questions, we take it as an indication that they need individualized assistance in understanding the $\mathrm{NIH}$ policy and copyright transfer issues. It is essential for authors to understand the distinctions between the "peer-reviewedaccepted manuscript" and the "published version," when a copyright transfer agreement is NIH policy-friendly or when using a Harvard-prepared NIH author addendum is required, and to understand the various workflows that will ultimately lead to acquiring a PMCID number. With tight grant deadlines often defining the schedule, we typically offer to meet for an individual consultation with the faculty member or administrative assistant. These meetings are helpful to us as well, since these faculty members frequently become partners who subsequently inform colleagues in the same department or lab about the policy and Countway's services.

As demand grew for Countway's assistance in complying with the NIH Public Access Policy, we considered how best to meet those needs, given finite staff resources. The recurrence of similar questions and problems helped us identify some processes for which we might develop automated solutions. Important questions for developing these tools included:

- Did the author(s) disclose to the publisher that the manuscript was supported by an NIH award?

- Does the publisher have a default policy whereby authors 
may archive their manuscripts in PubMed Central?

- Does the publisher have a strict policy whereby the author must disclose to the publisher that a manuscript has NIH support before a deposit in PubMed Central will be permitted?

- Did the corresponding author arrange to have the manuscript deposited, but fail to provide the necessary approvals after the NIH Manuscript Submission system sent a notification?

Figure 2 shows a sample submission workflow using publicly available online resources.

Navigating the necessary workflows can take different forms depending on where one is during the deposit or approval process. The process shown in figure 2 starts when a patron contacts HMScholar staff seeking a PMCID number, usually because a grant application is due. A lookup in PubMed might reveal that the number already exists or that it will be assigned by the NIH if the paper has been published in a PMC journal (in other words, one that regularly deposits its published content in PubMed Central). In both cases, the paper is compliant with the NIH policy.

On the other hand, if the lookup in PubMed reveals that there is no PMCID, then the next questions that need to be asked are whether the paper appeared in a peer-reviewed publication or whether, in fact, the paper actually resulted from work funded by NIH. If the answer to either of these questions is no, then the patron is notified that no PMCID is needed. However, if the answer is yes, then the next step is to do a lookup in the NIH system to see if the manuscript has been submitted. This can be done by using the PMID : PMCID Converter ${ }^{27}$ or through the My NCBI My Bibliography feature. If the manuscript has not been submitted, then a search of the SHERPA/ RoMEO system will in most cases provide

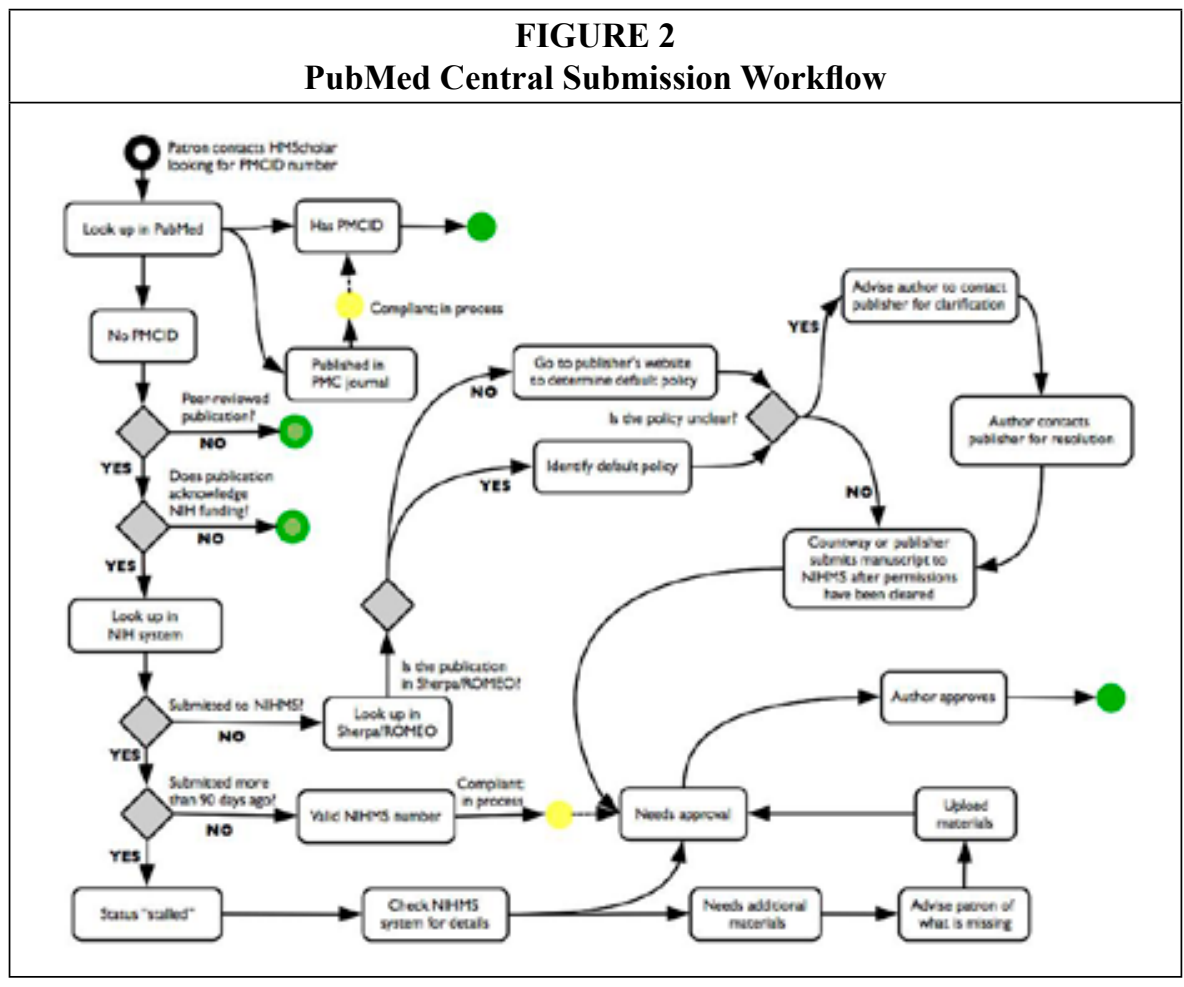


the needed information about publishers' policies with regards to authors' rights. ${ }^{28}$ If not, it becomes necessary to go directly to the individual publisher's website to determine what its policies are. If the policy is clear and allows for submission, then the paper can be submitted to NIH after permissions have been confirmed. If the policy is unclear, then authors will need to interact with their publisher directly to ensure that they do not violate copyright.

If the manuscript has recently been submitted to the NIHMS system, then it may not yet have a PMCID because it is still being processed by NIH. In that case, it will have a valid NIHMS number that can be used by the author in a current grant submission, provided that no more than 90 days postpublication have elapsed. In some cases, the submission can become stalled either because it needs the author's final approval (after NIH has converted the manuscript into its final PubMed Central format) or because there are missing materials, such as tables or figures. Once a submission is complete and all approvals have been given, the paper is assigned a PMCID and is, therefore, compliant with the NIH policy.

Teaching investigators how the NIH policy works and what investigators need to do prior to publication has been just one of our objectives. Another focus has been on discovering manuscripts that are "noncompliant" with the NIH policy. To address this directly and most effectively, we conducted an early experiment to measure the potential scope of NIH-funded manuscripts as compared to PubMed Central deposits (see figure 3).

As figure 3 illustrates, we parsed the PubMed XML to identify all articles that were published from April 2008 (when the mandatory NIH policy went into effect) to May 2009 (the time at which we conducted our study). Then, for each citation, we extracted the grants that were listed as having supported the work.

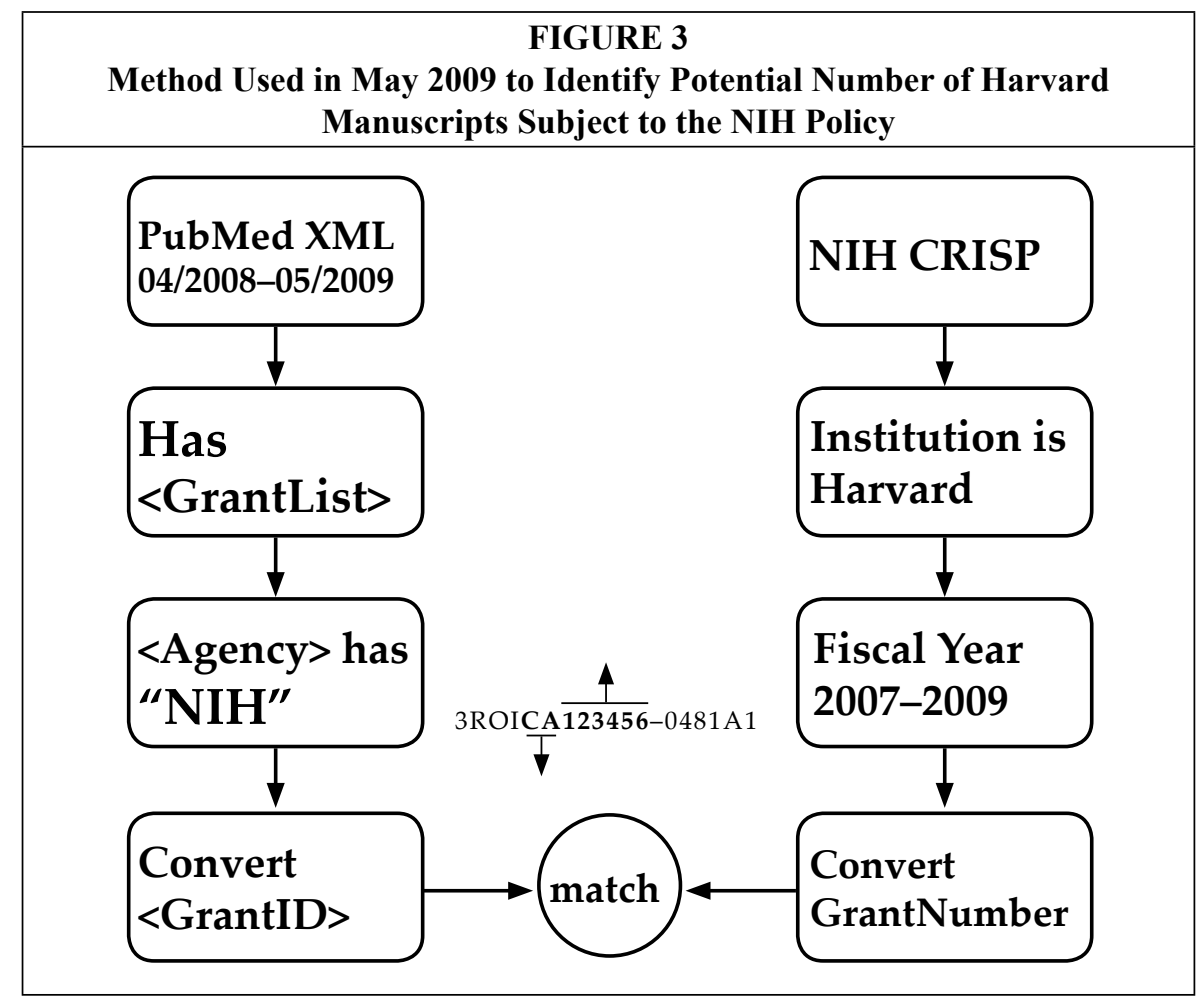


In many cases, we needed to convert the grant ID to its "core" number such that we would be able to match it to the data we extracted from CRISP, the NIH grant tracking system at the time. We then checked to see how many of the citations had an associated PMCID. The results of this investigation gave us an idea of where we stood at the time with regard to our PIs' compliance with this new mandate.

We were invited to present our results to NIH staff at a summer 2009 PubMed Central meeting at the NIH, and this led to an expanded collaboration with the NIH Office of Extramural Research. It happened that PubMed Central staff were already developing a similar regular reporting system for use at all universities. Shortly after the PubMed Central meeting, the NIH provided us with regular access to the Harvard-specific data, giving us ongoing and up-to-date information on all compliant and noncompliant Harvard manuscripts. These data allow us to see which departments and institutions would benefit most from a more aggressive outreach campaign and which PIs might be having the most difficulty complying with the policy.

\section{Results}

\section{Education}

Over the course of the last four years, we have engaged thousands of participants at Harvard and its affiliated institutions in conversations about the challenges and benefits of sharing published research openly and freely. We have offered nearly 200 seminars involving approximately 1,800 individuals. Some of these seminars were held at the library, but many more involved invited presentations at faculty and other departmental meetings. In addition, we have engaged in over 3,000 individual consultations, involving faceto-face conversations as well as phone call and e-mail exchanges.

\section{Collaboration}

Over the last several years, we have engaged in both internal and external collaborations. We have worked with our grants management colleagues both at the university level as well as locally at Harvard Medical School. Our librarian colleagues at the Harvard-affiliated hospitals have worked with us in outreach activities and also in introducing us to their local grants management specialists. Our ongoing collaboration with the NIH Office of Extramural Research has allowed us to track Harvard's compliance with the NIH policy on a regular basis and has made it possible for us to engage in highly specific and targeted outreach activities.

The NIH has provided us with access to information that allows us, at any given time, to view the total number of manuscripts within the scope of the NIH policy at Harvard and its affiliated institutions that:

- Have been successfully deposited to PubMed Central, and are, therefore, considered "compliant";

- Have not been submitted to PubMed Central, and are, therefore, considered "noncompliant";

- Are "in-process"-manuscripts that have been submitted to PubMed Central and to which a valid NIHMSID number has been issued within three months of publication; and

- Are "stalled submissions" - manuscripts that have been submitted to the NIHMS system, but which have yet to be approved by the author or PI.

When we received the first reports from NIH, the median compliance rate of HMS and its affiliated institutions was 68 percent, with a range of 44 to 76 percent; most recently, after two years and following our many outreach activities during that time period, the median compliance rate was 80 percent, with a range of 61 to 86 percent. The institutions with which we have worked most closely all have compliance rates in the range of 81 to 86 percent, which is well above the national average. $^{29}$ 


\section{Online Tools}

To simplify the process of successfully depositing a manuscript in PubMed Central (illustrated in figure 2 above), we developed a web-based application, called Public aXis, that navigates the required workflows from within a single dynamic web service.

The application, called Public aXis, is built on open source technologies, including Apache Cocoon, a web application framework, and eXist, an XML database, and it uses several open URL and API (application programming interface) access points to present data relevant to the most common questions in a single table of results. Knowing that the external API utilities we would need to interact with (Sherpa/RoMEO, NCBI-Entrez Utilities) would be providing us with XML structured data, managing these data by developing XSLT pipelines within Cocoon provided the most flexibility. The XSLT programs are freely available to any institution upon request. Figure 4 shows a screen shot of the Public aXis utility.

The tool allows the user to browse by institution, view a variety of statistics, including the total number of NIHsupported publications at Harvard, and query by grant number, PI name, author, or PubMed ID number. The Public aXis

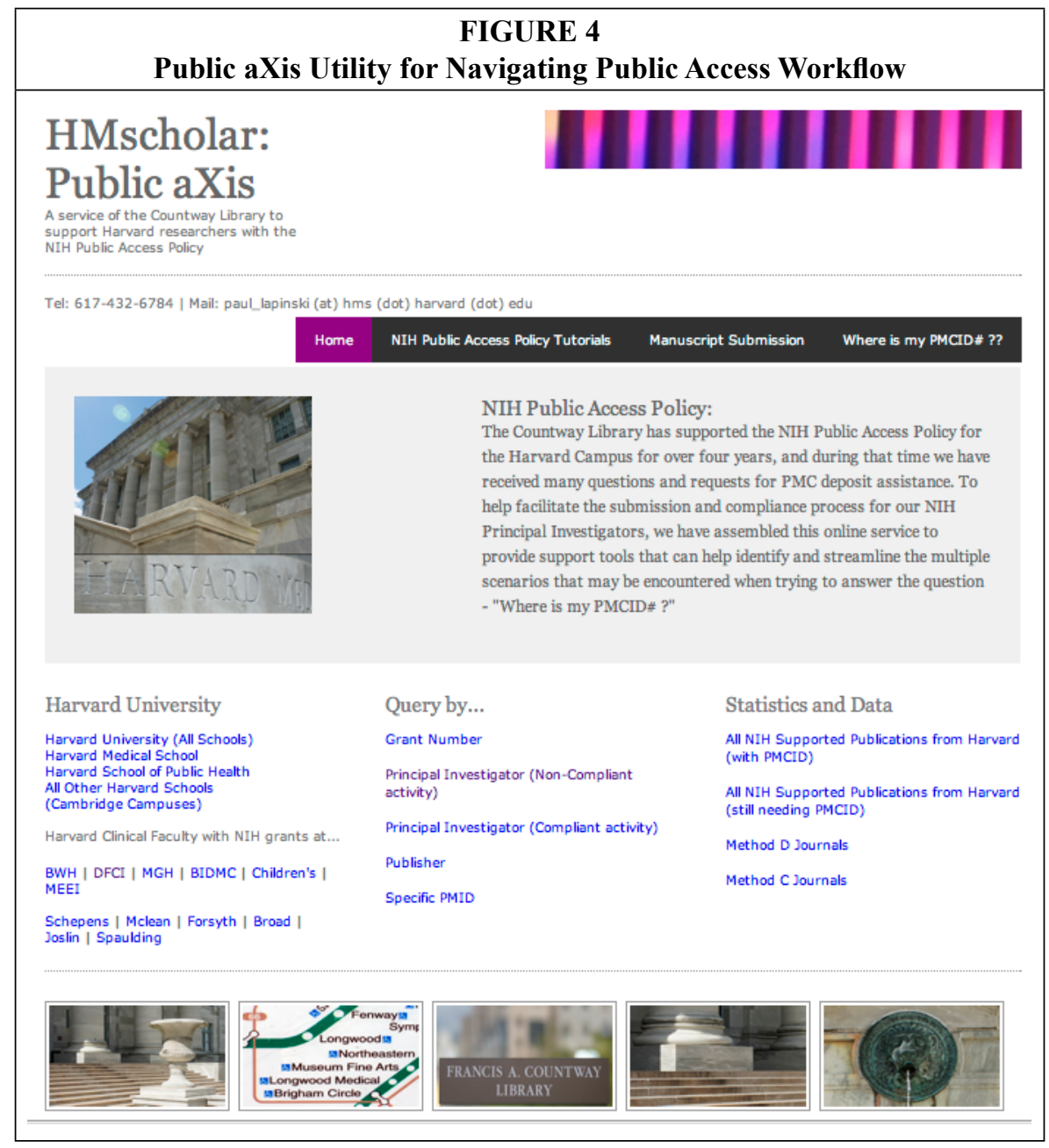


utility has become a key tool for easing the process of managing manuscripts that are within the scope of the NIH Public Access Policy.

\section{Discussion}

Through the HMScholar initiative, Countway has forged new allies and partnerships both within and beyond Harvard University. Since NIH grant activity is extensive at the research labs and clinics of the affiliated hospitals, it has been crucial to develop outreach programs at these locations. Common concerns and recurring questions by our PIs have helped us develop tools to streamline workflows to quickly address the NIH Public Access Policy compliance issues.

Having regular access to data provided by the NIH allowed us to further customize our regular seminars about the NIH policy and speak to the immediate concerns that a particular group of researchers might have. The response has been quite positive, and the ability to provide a brief list of noncompliant manuscripts for a given group of faculty members demonstrated immediately why monitoring and properly navigating this process was critical. It often allowed the presenter to show faculty in the audience how to address a real-time noncompliant issue well ahead of the next NIH grant deadline. Working from the current listing of noncompliant manuscripts also fostered new alliances with administrative assistants charged with managing their department's bibliographies for NIH biosketches and NIH grant progress reports.

Critical to the success of the HMScholar initiative have been the data provided by our collaborators at NIH. Reporting these figures in discussions at affiliated institutions helped emphasize the importance of educating the research community about the NIH policy. The data were extremely helpful in discussions with grants officers at each of the institutions, who then helped us identify other appropriate avenues to educate investigators and grant coordinators about the policy.
The grants officers often engaged in their own outreach campaigns, contacting PIs and informing them that Countway and local hospital librarians were their allies in resolving issues with noncompliant manuscripts that still needed to be deposited in PubMed Central.

The administrators serving PIs and department chairs throughout Harvard and its affiliates have also become key allies in helping educate researchers about the details of the NIH policy. As a result, Countway has formed a network of knowledgeable staff throughout Harvard who are able to understand the importance of timely compliance. Frequently, it is through their motivation to ensure that new faculty, postdoctoral fellows, and trainees understand the NIH policy that Countway staff are invited to speak at faculty meetings, research fellowship seminars, and noon-hour conferences.

\section{Conclusions}

Supporting the NIH Public Access Policy at a major research institution can be a daunting task. Perhaps the biggest challenge is the reticence among faculty to actively contribute manuscripts to the NIH PubMed Central repository. Even if investigators agree with the principles of public access, the details of identifying, uploading, and finalizing an online record can seem overwhelming or may be perceived as yet another bureaucratic burden. We have found that these issues are easily addressed by providing researchers with a centralized mechanism for facilitating manuscript submission to PubMed Central and by providing oneon-one support for any problems related to the NIH Public Access Policy.

In addition, we engaged in an active and sustained public outreach and education program. As a result, we have developed close relationships with many individuals across our campus and affiliated institutions..$^{30}$ Faculty, staff, and grants administrators all know that they can rely on Countway librarians to help them understand and fully comply with 
the federal requirements for making the results of Harvard's NIH-funded research broadly accessible to the public.

The work reported here has implications beyond compliance with the NIH Public Access Policy. The federal government has recently sought comments on a potential policy that would provide public access to peer-reviewed publications resulting from all federally funded research. ${ }^{31}$ Whether or not a new government-wide policy is the result, the discussions and deliberations about improved access to scientific publications are becoming increasingly vocal and visible. Librarians and other information specialists at academic institutions are well positioned to play a major role in influencing policies that result in open scholarly communication and in ensuring that those policies are implemented in a timely and effective manner. ${ }^{32}$

\section{Acknowledgments}

The authors would like to thank the NIH Office of Extramural Research and the NCBI PubMed Central staff not only for their generosity in providing us with the data that allow us to track the Harvard publications that are subject to the NIH Public Access Policy, but also for the support they have shown us throughout this continuing project.

\section{Notes}

1. Congress of the United States of America. Consolidated Appropriations Act, 2008. 110, HR 2764.

2. Laura Gordon-Murnane, "CREATIVE COMMONS: Copyright Tools for the 21st Century," Online 34, no. 1 (2010): 18-21.

3. Janice Hopkins, "Researchers Funded by NIH are Failing to Make Data Available," BMJ: British Medical Journal (International Edition) 332, no. 7543 (2006): 684.

4. Molly C. Barnett and Molly W. Keener, "Expanding Medical Library Support in Response to the National Institutes of Health Public Access Policy," Journal of the Medical Library Association 95, no. 4 (2007): 450-53; Merle Rosenzweig, Anna E. Schnitzer, Jean Song, Scott Martin, and Jim Ottaviani, "National Institutes of Health Public Access Policy and the University of Michigan Libraries' Role in Assisting with Depositing to PubMed Central," Journal of the Medical Library Association 99 (2011): 97-99; Nancy F. Stimson, "National Institutes of Health Public Access Policy Assistance: One Library's Approach," Journal of the Medical Library Association 97, no. 4 (2009): 238-40; Molly Keener and Cathy C. Sarli, "Public Access Policy Support Programs at Libraries: A Roadmap for Success," College E Research Libraries News 71, no. 10 (2010): 539-42.

5. Michael Carroll, Complying with the NIH Public Access Policy: Copyright Considerations and Options (Washington, D.C.: Scholarly Publishing and Academic Research Coalition, 2008).

6. Harvard University Guidelines: NIH Public Access Policy, available online at https://www. countway.harvard.edu/menuNavigation/libraryServices/nihPublicAccess.html [accessed 19 June 2012].

7. This is often referred to as the "serials crisis." Each year the Library Journal publishes its Periodical Price Survey, which represents in tabular form the increase in journal prices according to discipline. The current report is by Stephen Bosch and Kittie Henderson. (2012). "Coping with the Terrible Twins I Periodicals Price Survey 2012," Library Journal, 137(10), 10-10.

8. SHERPA, based at the University of Nottingham, U.K., is a consortium that is concerned with issues in open scholarly communication and is available online at www.sherpa.ac.uk/ [accessed 19 June 2012]; the SHERPA/RoMEO service is a SHERPA project that provides up-to-date information about publishers' copyright and self-archiving policies; available online at www. sherpa.ac.uk/romeo/ [accessed 19 June 2012].

9. Association of Research Libraries, Federal Research Public Access Act, available online at www.arl.org/sparc/advocacy/frpaa/ [accessed 19 June 2012].

10. Golnessa Galyani Moghaddam, "Why Are Scholarly Journals Costly Even with Electronic Publishing?" Interlending E Document Supply 37, no. 3 (2009): 149-55.

11. Donald W. King, "The Cost of Journal Publishing: A Literature Review and Commentary," Learned Publishing 20, no. 2 (2007): 85-106.

12. Raym Crow, "Income Models for Open Access: An Overview of Current Practice," Scholarly Publishing and Academic Resources Coalition (2009), available online at www.arl.org/sparc [accessed 19 June 2012]; this study, while focused primarily on book publishing, gives a good review of 
some possible business models. Lynne Withey et al., "Sustaining Scholarly Publishing: New Business Models for University Presses: A Report of the AAUP Task Force on Economic Models for Scholarly Publishing," Journal of Scholarly Publishing 42, no. 4 (July 2011): 397-441.

13. Robert Campbell and Alice Meadows, "Scholarly Journal Publishing: Where Do We Go from Here?" Learned Publishing 24, no. 3 (July 2011): 171-81; Angus Phillips, "Blog to the Future? Journals Publishing in the Twenty-First Century," Journal of Scholarly Publishing 42, no. 1 (Oct. 2010): 16-30; Michael Jubb, Joel Cook, Daniel Hulls, David Jones, and Mark Ware, "Costs, Risks and Benefits in Improving Access to Journal Articles," Learned Publishing 24, no. 4 (Oct. 2011): 247-+.

14. Philip Bernstein, Barbara Cohen, Catriona MacCallum, Hemai Parthasarathy, Mark Patterson, and Vivian Siegel, "PLoS biology -We're Open," PLoS Biology 1, no. 1 (Oct. 2003): E34; the Public Library of Science now encompasses seven journals, including its most recent experiment, PLoS ONE. Catriona J. MacCallum, "ONE for All: The Next Step for PLoS," PLoS Biology, no. 4 (2006): E401; online site: PLoS: Leading a Transformation in Research Communication, available online at http://plos.org/ [accessed 19 June 2012]. 2012].

15. Directory of Open Access Journals, available online at http://doaj.org [accessed 19 June

16. OpenDOAR and ROARMAP are online directories for open access repositories and policies, respectively. OpenDOAR lists academic open access repositories and allows searching of repository contents. ROARMAP provides a listing of all open access policies, browsable by country or by type, such as institutional mandates or funder mandates; available online at www.opendoar. org/ and http://roarmap.eprints.org/ [accessed 19 June 2012].

17. Peter Suber's book about open access has just been published. Peter Suber, Open Access (Cambridge, Mass: The MIT Press, 2012); another source of general information about open access issues is Suber's "Open Access Overview," available online at http://bitly.com/oa-overview [accessed 19 June 2012]; Alma Swan's recent report to UNESCO is intended for policy makers and gives a comprehensive review of the open access movement, including its history, benefits, and strategies to promote it. Alma Swan, "Policy Guidelines for the Development of Promotion of Open Access," United Nations Educational, Scientific and Cultural Organization (2012).

18. Budapest Open Access Initiative (2002), available online at www.soros.org/openaccess/ read [accessed 19 June 2012].

19. Carolina Rossini, "Access to Knowledge as a Foundation for an Open World," Educause Review 45, no. 4 (2010): 60-68; Alesia Zuccala, "Open Access and Civic Scientific Information Literacy," Information Research-an International Electronic Journal 15, no. 1 (Mar. 2010); Alliance for Taxpayer Access, "Patients \& Patient Groups Support Public Access to Research," available online at www.taxpayeraccess.org/supporters/patient-groups/ [accessed 19 June 2012]; Paul Wicks, “Open Access Is Not for Scientists. It's for Patients," Speaking of Medicine: PLoS Medicine Community Blog (June 14, 2012), available online at http://blogs.plos.org/speakingofmedicine/2012/06/14/ open-access-is-not-for-scientists-its-for-patients/ [accessed 19 June 2012].

20. Philip M. Davis and William H. Walters, "The Impact of Free Access to the Scientific Literature: A Review of Recent Research," Journal of the Medical Library Association 99, no. 3 (Jul 2011): 208-17; Chris Armbruster, "Open Access Policy Implementation: First Results Compared," Learned Publishing 24, no. 4 (Oct. 2011): 311-+; Rowena Cullen and Brenda Chawner, "Institutional Repositories, Open Access, and Scholarly Communication: A Study of Conflicting Paradigms," Journal of Academic Librarianship 37, no. 6 (Dec. 2011): 460-70.

21. Ji-Hong Park, "Motivations for Web-Based Scholarly Publishing: Do Scientists Recognize Open Availability as an Advantage?" Journal of Scholarly Publishing 40, no. 4 (Jul. 2009): 343-69; Jingfeng Xia, "An Anthropological Emic-Etic Perspective on Open Access Practices," Journal of Documentation 67, no. 1 (2011): 75-94.

22. Some examples are the Office for Scholarly Communication, Harvard University Library, University of California Libraries, Scholarly Communications Office at Duke University, and the Collections and Communications Office at Arizona State University; available online at http://osc. hul.harvard.edu/, libraries.universityofcalifornia.edu/scholarly/, http://library.duke.edu/about/ depts/scholcomm/, http://lib.asu.edu/colldev [accessed 19 June 2012].

23. Richard Gedye, "Open Access Is Only Part of the Story," Serials Review 30, no. 4 (2004): 271-74; Emma Cryer and Maria Collins, "Incorporating Open Access into Libraries," Serials Review 37, no. 2 (June 2011): 103-07; Maitrayee Ghosh, "Information Professionals in the Open Access Era: The Competencies, Challenges and New Roles," Information Development 25, no. 1 (Feb. 2009): 33-41.

24. Kristi L. Palmer, Emily Dill, and Charlene Christie, “Where There's a Will There's a Way? Survey of Academic Librarian Attitudes About Open Access," College \& Research Libraries 70, no. 4 (July 2009): 315-35.

25. Andrea A. Wirth and Faye A. Chadwell, “Rights Well: An Authors' Rights Workshop for 
Librarians," portal: Libraries and the Academy 10, no. 3 (July 2010): 337-54. In an effort to assist libraries and librarians in making the transition to fuller engagement in scholarly communication activities, the Association of College and Research libraries and the Association of Research Libraries jointly sponsor the Institute on Scholarly Communication "to promote the development of library-led outreach on scholarly communication issues." ACRL/ARL Institute on Scholarly Communication is available online at www.ala.org/acrl/issues/scholcomm/scinstitute [accessed 19 June 2012].

26. Maria Carpenter, Jolie Graybill, Jerome Offord Jr., and Mary Piorun, "Envisioning the Library's Role in Scholarly Communication in the Year 2025," portal: Libraries and the Academy 11, no. 2 (Apr. 2011): 659-81.

27. PMC : PMCID Converter, available online at www.ncbi.nlm.nih.gov/sites/pmctopmid [accessed 19 June 2012].

28. Mary M. Case, "Scholarly Communication: Arl as a Catalyst for Change," portal: Libraries and the Academy 9, no. 3 (Jul 2009): 381-95; Scholarly Publishing and Academic Resources Coalition (SPARC), available online at www.arl.org/sparc/ [accessed 19 June 2012].

29. Neil Thakur, Special Assistant to the NIH Deputy Director for Extramural Research, has stated that NIH is currently at about 75 percent compliance (personal communication, January 2012).

30. In a recent article, Malenfant makes a persuasive case that academic libraries that make a sustained effort to reach out to faculty about scholarly communication raises the overall visibility of the library and allows the library to take on a variety of additional leadership roles at the university. Kara J. Malenfant, "Leading Change in the System of Scholarly Communication: A Case Study of Engaging Liaison Librarians for Outreach to Faculty," College and Research Libraries 71 (Jan. 2010): 63-76.

31. Request for Information: Public access to peer-reviewed scholarly publications resulting from federally funded research. The request for information is in accordance with the America COMPETES Reauthorization Act of 2010 and "offers the opportunity for interested individuals and organizations to provide recommendations on approaches for ensuring long-term stewardship and broad public access to the peer-reviewed scholarly publications that result from federally funded scientific research. The public input provided through this Notice will inform deliberations of the National Science and Technology Council's Task Force on Public Access to Scholarly Publications." Available online at www.gpo.gov/fdsys/pkg/FR-2011-11-04/html/2011-28623.htm [accessed 19 June 2012].

32. In the 18 months that have elapsed since this article was written, several new pieces of Public Access legislation have been introduced in Congress; the White House OSTP issued an Executive Order in February 2013 that will likely result in improved access not only to research articles but also to data; and the NIH began enforcing public access compliance more strictly. These and other developments have prompted many enhancements to our HMscholar services over the last year and a half. 